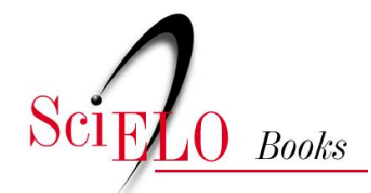

\title{
Introdução \\ O nascimento de uma universidade
}

\section{Durval Rosa Borges}

\section{SciELO Books / SciELO Livros / SciELO Libros}

BORGES, DR. Introdução: o nascimento de uma universidade. In RODRIGUES, J., org., NEMI, ALL., LISBOA, KM., and BIONDI, L. A Universidade Federal de São Paulo aos 75 Anos: ensaios sobre história e memória [online]. São Paulo: Unifesp, 2008. pp. 17-27. ISBN: 978-85-61673-83-3.

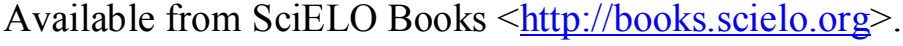

\section{(1) (1)(2)}

All the contents of this work, except where otherwise noted, is licensed under a Creative Commons Attribution-Non Commercial-ShareAlike 3.0 Unported.

Todo o conteúdo deste trabalho, exceto quando houver ressalva, é publicado sob a licença Creative Commons Atribuição Uso Não Comercial - Partilha nos Mesmos Termos 3.0 Não adaptada.

Todo el contenido de esta obra, excepto donde se indique lo contrario, está bajo licencia de la licencia Creative Commons Reconocimento-NoComercial-CompartirIgual 3.0 Unported. 


\title{
Introdução
}

\section{O Nascimento de uma Universidade}

\author{
Durval Rosa Borges
}

ESTE LIVRO CONTA A HISTÓRIA de uma escola privada de medicina que se transformou em universidade pública. É dupla a comemoração: celebra-se uma história de sucesso e testemunha-se o nascimento de uma universidade. Ao longo de 75 anos foi sendo construído um modelo de universidade pública apoiada por entidades de direito privado sem finalidade econômica: uma associação mantenedora de seu hospital-escola e uma fundação de apoio a suas atividades de ensino, de pesquisa e de extensão. Alguns episódios foram decisivos na construção deste modelo.

\section{Escola Paulista de Medicina e Hospital São Paulo}

O ensino superior no Brasil é recente, mesmo quando comparado ao de outros países das Américas: o primeiro curso de ensino superior instalado no país acaba de completar duzentos anos. Por decisão do príncipe regente D. João vi, a Escola de Cirurgia da Bahia foi criada em I 8 de fevereiro de I 808. A Escola Paulista de Medicina (EPM) foi fundada em I933, época associada ao nascimento da medicina moderna: "É habitual datar o começo da medicina moderna em algum ponto no meio dos anos de I930, com a inserção da sulfonamida e da penicilina na farmacopéia, e é costumeiro atribuir a esses eventos a força da revolução na prática médica” ${ }^{\mathrm{I}}$.

\footnotetext{
I. "It is customary to place the date for the beginnings of modern medicine somewhere in the mid-I930s, with the entry of sulfonamides and penicillin into the pharmacopoeia and it is usual to ascribe to these events the force of a revolution in medical practice". Lewis Thomas, "Medical Lessons from History", The Medusa and the Snail.
} 
Em I ${ }^{\circ}$ de junho de 1933 foi publicado o manifesto de fundação da EPM, assinado por 3 I médicos e dois engenheiros, com idades que variavam de 26 a 54 anos (mediana de 34 anos). O manifesto explicitou o duplo objetivo da iniciativa:

Uma escola médica exige instalaçôes hospitalares para o ensino das clínicas, e a criação de seu hospital não será menor serviço prestado a São Paulo pela nova Escola que, só por isso, faria jus ao maior carinho e ao melhor desvelo por parte da população paulista. A premência desses dois problemas - o do ensino médico e o da assistência hospitalar - bastaria para justificar amplamente a presente iniciativa.

Para o cumprimento do duplo objetivo foi constituída a "Sociedade Civil Escola Paulista de Medicina”, sob a liderança de Octávio de Carvalho (I89I-I973), com prazo determinado de cinqüenta anos de existência. Esta limitação indicava que os fundadores previam que passado aquele período seria necessária reavaliação do ordenamento jurídico da entidade. $\mathrm{Na}$ fase inicial os alunos pagavam para estudar e os fundadores pagavam para ensinar:

O patrimônio da Escola é constituído pelas importâncias em dinheiro exibidas por seus sócios-fundadores, no ato inicial da constituiçẫo da sociedade, e pelas demais quantias com que os mesmos se comprometeram a entrar, nos prazos convencionados, até a integralizaçáo total da quota de capital cuja responsabilidade, cada um de per si, tiver assumido"2.

O Hospital Sáo Paulo (HSP) foi o primeiro hospital-escola a ser construído no Brasil, e na cerimônia do lançamento da estaca fundamental em 1936 já podia declamar o poeta Guilherme de Almeida: "Aí está, germinada e prosperada a semente; aí está, florescido o ideal; aí está, frutificado o empreendimento! Aí está a Escola Paulista de Medicina. A árvore boa, em boa hora, sob um bom signo, numa boa terra e por boas mãos plantada”. Em I 938 a EPM foi reconhecida oficialmente e diplomou a primeira turma de médicos. Logo a seguir iniciou-se o curso de enfermeiras (1939) e, em I940, o HSP já funcionava com cinco andares.

2. Estatutos da Escola Paulista de Medicina, 1933, artigo 3 .

\section{Núcleo da Pesquisa}

Em I937 a EPM contratara o médico José Ribeiro do Valle (1908-2000) para ensinar farmacologia, e em I943, o também médico mineiro José 
Leal Prado (I918-i987) para ensinar química fisiológica. Professores da área clínica aliavam o ensino ao empenho em construir, equipar e fazer funcionar o HSP. Os professores Valle e Leal completavam sua atividade didática com a de pesquisa, no Instituto Butantan. Convencidos, porém, da necessidade de permanecer em tempo integral na EPM organizaram o Laboratório de Farmacologia e Bioquímica que, em dezembro de I947, foi instalado em sala anexa à Farmácia no segundo andar do Hospital São Paulo. No dizer de Valle, "a pesquisa básica apenas se esboçava e era preciso dinamizá-la sem tardança. Leal Prado e eu metemos mãos à obra..." No período de cinco anos (I948 a I953) o Laboratório desenvolveu-se a ponto de exigir instalaçóes próprias e independentes e em meados de 1956 instalou-se em edifício próprio, o hoje denominado Edifício José Leal Prado. Neste ambiente Valle e Leal formaram equipes, buscaram financiamento e lideraram o desenvolvimento de duradouras linhas de pesquisa: endocrinologia experimental (Valle) e sistemas de peptídeos vasoativos (Leal Prado). O Laboratório de Farmacologia e Bioquímica foi o núcleo da pesquisa na EPM e deu origem aos atuais departamentos de Bioquímica, de Farmacologia, de Biofísica e de Psicobiologia da Universidade Federal de São Paulo.

\section{Regime Departamental}

A criação do Departamento de Medicina em I95 I, ainda na Escola privada, por iniciativa de Jairo Ramos (I900-I972), representou, em princípio, o fim do regime de cátedras. A proposta vinha de 1949 e, para entender porque foram necessários dois anos para sua implantação, basta lembrar que o então diretor do Departamento de Ensino Superior do Ministério da Educação aconselhava que a Escola Paulista de Medicina estudasse o assunto com cautela, principalmente com referência ao futuro, pois, "o que se pretendia era uma inovação no ensino médico, e traria conseqüências que deveriam ser bem ponderadas". O programa de ensino deixava de ser decisão individual de cada catedrático. Outros departamentos foram se estruturando até que, em I 965, a EPM foi organizada em doze departamentos, quando uma lei federal institui oficialmente o sistema departamental na universidade brasileira.

No ano de 195 I foram criados o Conselho Nacional de Pesquisas (CNPq), a Coordenação de Aperfeiçoamento de Pessoal de Nível Superior (Capes) e a Associação Médica Brasileira, e realizou-se a I $\mathbf{a}$ Bienal de Artes Plásticas de São Paulo. A Fapesp foi instituída em I962. 


\section{Federalização da Escola}

Não foram necessários os cinqüenta anos previstos para a reavaliação do ordenamento jurídico da instituiçáo. O crescimento, tanto da EPM como de seu hospital-escola, levou a Sociedade mantenedora de ambos a séria crise, após vinte anos de existência. Componentes desta crise podem ser percebidos na ata da $85^{\underline{a}}$ Reuniáo da Congregaçáo ( 8 de abril de 1954) reunida (às 22:00h) para analisar o pedido de renúncia do então diretor:

O senhor diretor, professor doutor Jairo de Almeida Ramos, passa a expor à Congregação os motivos que determinaram sua demissão em caráter irrevogável. Informa que o motivo principal e quase único de seu pedido de demissão, não se prendia ao cansaço físico de sua pessoa, e sim ao cansaço psicológico. Como sabem tem trabalhado até o presente momento em condiçóes desfavoráveis. Há dois anos que vem procurando desenvolver suas atividades em todos os setores e baldados têm sido seus esforços. É possivelmente uma questáo de temperamento, porém nấo se sente satisfeito com ele próprio e isto o faz sofrer mais do que seus companheiros de Congregação imaginam. Referese ao desinteresse que vem notando com os problemas capitais da Escola, por parte de alguns professores; diz ainda que todos estấo cientes que ao assumir a diretoria, a Escola Paulista de Medicina atravessa uma crise séria; teve que enfrentar graves problemas e mal entendidos e, para harmonizar em parte esses grandes problemas abdicar de sua personalidade; seu único interesse e desejo era e é de dar o melhor para todos, entretanto, pouco conseguira fazer. Passa em seguida a fazer uma recapitulaçáo de todas as atividades que procurou desenvolver principalmente pela promessa de auxílio que receberia do Senhor Governador e que falhara; Escola de Puericultura que não conseguira o capital necessário para sua construção até o presente momento; o desejo de passar a Escola em Fundaçáa, que em virtude do débito para com a Caixa Econômica Federal, também falhara; as promessas feitas pelo Senhor Governador e Prefeito da Capital, por ocasiáo dos festejos comemorativos ao $20^{\circ}$ Aniversário da Fundação da Escola Paulista de Medicina, que também falharam. Passa a discorrer sobre as dificuldades que foram criadas com o diretor clínico, que muito é necessário no Hospital São Paulo, porquanto diz que o diretor não tem possibilidade de atender a todos os casos que surgem dentro do Hospital, porquanto a administração é complexa. Reporta-se ainda a necessidade que se vê em alguns laboratórios da Escola, que mal tem um mínimo indispensável. Diz ainda que a Escola tem perdido elementos humanos bons porque a Escola nâo pode pagar. Acha que explicadas estas razóes é fácil de supor os motivos que determinam sua demissão em caráter irrevogável. 
O desfecho da crise ocorreu com a federalização da instituição privada. Foi decisão polêmica: quando a idéia fora inicialmente discutida pela Congregação, ainda em 1950, fora aprovada pela estreita margem de catorze votos a favor e treze contra. A lei 2.7I2 de janeiro de 1956 que federalizou a EPM não incluiu o HSP, seu hospital-escola. Com a federalização, a União recebeu parte do patrimônio da Sociedade Civil, assumiu os compromissos da EPM e oficializou trinta professores catedráticos então em atividade. A contabilidade da Sociedade já vinha sendo desdobrada em duas, uma relativa à Escola e outra ao Hospital São Paulo. A lei da federalização ainda determinou que "para o ensino das clínicas da Escola Paulista de Medicina, a entidade mantenedora do Hospital São Paulo assegurará, mediante cláusula na escritura referida neste artigo, a utilização de suas enfermarias gerais, instalaçóes e equipamentos, independente de qualquer indenização". Para evitar a duplicidade de nomes, quatro anos após a federalização, em junho de 1960, a Sociedade Civil Escola Paulista de Medicina (mantenedora agora apenas do HSP e náo mais da EPM) passou a denominar-se Sociedade Paulista para o Desenvolvimento da Medicina (SPDM). Iniciou-se assim a criação de um modelo onde uma escola médica vinculada ao Ministério da Educação tinha seu hospital-escola mantido por sociedade de caráter privado. A formaçáo médica no complexo EPM/HSP completou-se quando em 1957 foram iniciados programas de Residência Médica, conseqüência da anterior criaçáo do regime de internato no curso de graduação.

\section{O Desencontro}

Em dezembro de 1960 a lei 3.835 (federaliza a Universidade da Paraíba e dá outras providências), um dos últimos atos do governo Juscelino Kubitschek, trazia embutida (artigos I I e I 2) a criação da Universidade Federal de São Paulo (UfSP). Esta teria sede na cidade de São Carlos e seria constituída por cinco estabelecimentos de ensino superior: Escola Paulista de Medicina, Escola de Engenharia de São Carlos, Faculdade de Filosofia, Ciências e Letras de Araraquara, Faculdade de Farmácia e Odontologia de Araçatuba e Faculdade Municipal de Ciências Econômicas de Santo André. Entretanto a UfSP dependia de legislaçáo complementar para sair do papel, o que náo aconteceu durante o breve período de Jânio Quadros na presidência da República. Foi apenas em dezembro de 1963 que um decreto do Presidente Joáo Goulart criou o Conselho Consultivo da UFSP com o objetivo de implantá-la, determinando o início de seu efetivo funcionamento para o ano letivo de 
I964. O Conselho foi presidido por Marcos Lindenberg (I90 I-I979), entâo diretor da Escola Paulista de Medicina, e contava com outros sete membros dentre os quais Fernando Henrique Cardoso, representando a Universidade de São Paulo. Nesta primeira tentativa de criação de uma universidade federal em Sáo Paulo, a EPM de certo modo deixaria de ser condutora de seu destino: náo seria sede da reitoria e seria incorporada a um conjunto de instituiçóes isoladas de ensino superior profissionalizante com as quais não mantinha relação acadêmica e que traziam heterogênea tradição em pesquisa. A lógica de agregação possivelmente fosse a complementaridade dos cursos de graduação oferecidos pelas diferentes instituiçóes. Porém, com a mudança de regime político em abril de 1964, a UFSP foi desfeita e a EPM transformada em estabelecimento isolado de ensino superior de natureza autárquica.

\section{O Curso de Ciências Biomédicas e a Pós-Graduação}

Em I 966 foi criado na Escola o curso biomédico, que pode ser considerado o embriấo da futura universidade e antecipou a ação da Capes, que na década seguinte normatizou o desenvolvimento de cursos de pós-graduação stricto sensu. José Leal Prado finaliza o documento "Sobre o curso de graduaçáo, mestrado e doutoramento em ciências biomédicas da Escola Paulista de Medicina" com o seguinte parágrafo:

Em anos recentes foi feita uma tentativa malograda de fundar-se em São Paulo Universidade Federal. Entretanto, uma instituição como a Escola Paulista de Medicina sente-se limitada dentro da estrutura de um instituto isolado de ensino superior. A criação do curso de ciências biomédicas tornará mais amplo seu campo de atividade cultural e mais importante sua contribuição social. Se tivermos êxito nesta iniciativa, estaremos armazenando uma experiência valiosa ao mesmo tempo em que teremos maiores possibilidades para fazer uma segunda tentativa no caminho da Universidade Federal. Somente o futuro ditará a melhor conduta a seguir.

O credenciamento pela Capes dos primeiros programas formais de pós-graduaçáo stricto sensu na EPM, a partir de I972, ampliou a pesquisa nas áreas básicas, consolidou a pesquisa nas áreas clínicas e estimulou a progressiva interdisciplinaridade da pesquisa. Os programas passaram a ser coordenados por uma Comissão de Pós-Graduação, que teve como primeiro presidente o prof. Ribeiro do Valle. Nas décadas seguintes a geração de professores "pós-fundadores" ampliou o ensino de graduaçáo, assumiu decidido compromisso com a iniciação 
científica, com a pós-graduação, com a pesquisa e com a inserção internacional, e procurou ativamente captar recursos para a instituição. A EPM passou a ter mais inscritos em programas de pós-graduação do que alunos matriculados em cursos de graduação. Amadurecia a idéia de uma universidade, estruturada em unidades de áreas do saber e não em um conjunto de faculdades ou de escolas profissionalizantes.

\section{A Universidade}

Em agosto de I979 o Ministério da Educação e Cultura solicitou à Escola que sugerisse como pretendia enquadrar-se em lei de I968 que tratava da incorporação de estabelecimento isolado de ensino superior em universidade federal ("Os estabelecimentos isolados de ensino superior deverão, sempre que possível incorporar-se a universidades ou congregar-se com estabelecimentos isolados da mesma localidade ou de localidades próximas, constituindo, neste último caso, federações de escolas, regidas por uma administração superior e com regimento unificado que lhes permita adotar critérios comuns de organização e funcionamento.”). Após avaliar o assunto e entender que a proposta de incorporação ou associação não atendia aos interesses e à história da EPM, a Congregação decidiu por unanimidade que a "Escola Paulista de Medicina oferece todas as condiçôes de estrutura e tradição para constituir o núcleo de uma universidade dedicada seriamente ao ensino e a pesquisa na área das ciências biológicas e da saúde". Mas foi apenas em dezembro de I994 que a lei 8.957 transformou a EPM em Universidade Federal de São Paulo (Unifesp), com a característica proposta, isto é, de ser universidade temática (universidade da saúde). A instituição ganhou autonomia acadêmica, passou a reconhecer seus diplomas, iniciou processo de reformulaçáo e avaliação de seus cinco cursos de graduação e elaborou seu Estatuto. Este manteve a estrutura departamental vigente e criou quatro próreitorias encarregadas de organizar as atividades de ensino, pesquisa e extensão da universidade. Iniciativas integradoras, como o Programa MD-PhD, puderam ser implantadas.

Em 2004 a Unifesp iniciou processo de expansão institucional com a instalação de novos campi e a criação de novos cursos de graduação, agora em áreas do conhecimento além do das ciências da saúde. Após dez anos de experiência a Unifesp deixou de ser universidade temática e passou a ter amplo espectro de cursos de graduação e de áreas de pesquisa. No modelo agora instalado de universidade a EPM não foi incorporada e não agregou instituiçôes previamente existentes. 
Conduziu o processo (non ducor duco) e imprimiu nos novos campi e nas novas áreas de atuação seu padrão de qualidade.

As decisóes de federalizar a EPM, de criar outros cursos além do de Medicina, de transformar a Escola em universidade temática e de posteriormente ampliar seu escopo, olhadas em perspectiva, parecem ter um encadeamento lógico e coerente. $\mathrm{Na}$ ocasião em que foram tomadas, cada uma das decisóes não pareceu transformadora, mas seu efeito cumulativo foi decisivo. Barreiras aparentemente intransponíveis precisaram ser vencidas. No início do século $\mathrm{XV}$ os navegadores portugueses ao atingirem o Cabo do Bojador retornavam, convencidos que haviam alcançado o fim do mundo. Em I 434, Gil Eanes lançou sua esquadra para o mar alto, contornando à distância e ultrapassando o Cabo. A manobra de navegaçáo em si (conhecida como volta do mar) foi trivial. A barreira representada pelo cabo não era física, era mental. Vencida a barreira, um novo mundo foi sendo conquistado.

\section{O Modelo Unifesp}

O relatório de atividades dos Laboratórios de Farmacologia e Bioquímica relativo ao período de 1953-1958, que inclui o ano de $1956 \mathrm{da}$ federalização, registrou:

A folha de pagamento do pessoal destes Laboratórios somou em 1958 Cr\$ 2.755.200,00 ou Cr\$229.600,00 mensais. Desse total 57\% representaram o pagamento efetuado diretamente pelo Governo da União por força da lei que federalizou a Escola Paulista de Medicina, e $43 \%$ a suplementação obtida de outras fontes. Nas rubricas Material e Manutenção a contribuição do Governo Federal guardou aquela proporção. Por conseguinte, para a atividade basal destes Laboratórios, ainda não é suficiente a verba oficial disponível. Daí a necessidade de se apelar para outras fontes a fim de aumentar a nossa receita. Na lista de auxílios aos Laboratórios de Farmacologia e Bioquímica, conseguidos de diversas fontes oficiais e particulares, o futuro estudioso dos problemas educacionais brasileiros poderá encontrar matéria digna de reparo. Sem tais auxílios, fazemos questão de acentuar, a atividade destes Laboratórios teria sido inexpressiva.

Fica claro que, para manter a excelência da instituição em pesquisa, e conseqüentemente no ensino, sempre foi preciso enfrentar o problema do financiamento, tanto privado (mensalidade paga pelos alunos no período de 1933 a 1956) como público (dotação orçamentária a partir de 1956). Com o crescimento da EPM e do HSP o problema acentuou-se 
e criaram-se ao longo dos anos, a partir de departamentos acadêmicos, instituiçóes ditas suplementares, com personalidade jurídica própria e que passaram a captar recursos, tanto privados como públicos. Simultaneamente à criação da Unifesp (lei 8.957/94) é editada a lei 8.958/94 ("a Lei Seguinte") que estipulou que "as instituiçóes criadas com a finalidade de dar apoio a projetos de pesquisa, ensino e extensão e de desenvolvimento institucional, científico e tecnológico de interesse das instituiçôes federais deverão estar constituídas na forma de fundaçôes de direito privado sem fins lucrativos”. Com exceção da Fundação Oswaldo Ramos (de apoio à Disciplina de Nefrologia) as demais instituiçóes chamadas de suplementares e criadas pelos departamentos não atendiam a esta lei, pois estavam constituídas na forma de associaçóes e não de fundações. Em maio de 2003 o Tribunal de Contas da União determinou que a Unifesp cumprisse a lei, regularizando seus órgãos suplementares. Após dois anos de tratativas, em maio de 2005, 3 I destes órgãos suplementares instituíram a Fundação de Apoio à Universidade Federal de São Paulo (Fap-Unifesp), de direito privado e sem finalidade econômica. A Fap-Unifesp foi a seguir reconhecida pelo Conselho Universitário e credenciada pelo Ministério da Educação e pelo Ministério da Ciência e Tecnologia como fundação de apoio à Unifesp.

Completou-se assim o modelo Unifesp: uma universidade pública apoiada por entidades de direito privado sem finalidade econômica. De um lado uma associação mantenedora do hospital-escola e de outro lado uma fundação com o objetivo de apoiar atividades de ensino, pesquisa e extensão. Durante décadas a SPDM apoiou iniciativas acadêmicas da EPM. Mas com a expansão, de um lado, da SPDM (que além do HSP desenvolve atividades de assistência à saúde em outros ambientes hospitalares ou ambulatoriais) e, de outro lado, da Unifesp, aquela não tinha mais condiçóes, nem razóes, para apoiar todas as atividades desta. Assim, a Fundação deve assumir o apoio a atividades e iniciativas da Unifesp, excluídos os serviços de assistência à saúde, que continuam sendo competência da SPDM.

\section{9. $\mathrm{O}$ Livro}

Este livro é de autoria de quatro professores de História da Unifesp, campus Guarulhos: Karen Macknow Lisboa ("Comemorações, Memória, História e Identidade”), Ana Lúcia Lana Nemi ("A Escola Paulista de Medicina entre Tradição e Modernidade”), Luigi Biondi (“Não Éramos Mais uma Universidade’: a Política na Escola Paulista de Medicina”), e Jaime Rodrigues (“Criação e Expansão da Unifesp: Marcos 
da Memória e da História Institucional"). São docentes de variada e rica formação acadêmica que foram auxiliados por alunos selecionados da primeira série do curso de História da Unifesp. Recém-chegados à Instituição os autores consultaram, com dedicação, sistemática e distanciamento, fontes primárias de informação, evitando assim o risco expresso por Oswald de Andrade na frase: "A gente escreve o que ouve - nunca o que houve". Além de livros e atas consultaram a coleção de publicaçóes do Centro Acadêmico Pereira Barretto (principalmente a revista $O$ Bíceps). Na coleção de $O$ Bíceps podem ser encontrados assuntos muitas vezes não discutidos amplamente nos documentos oficiais, principalmente durante o período ditatorial recente. Dois assuntos podem ser lembrados. Um primeiro foi a discussão sobre a reforma do regimento da ЕРM em I 964 cujo artigo 90 (finalmente excluído do texto final) determinava que o ensino fosse gratuito para o aluno que demonstrasse não poder pagar, o que na prática abolia o ensino gratuito na instituição. Um segundo exemplo foi o movimento estudantil pela federalização do Hospital São Paulo em i967/ 1968. O Bíceps chegou a publicar que após uma greve de quarenta dias, no dia I $^{\circ}$ de fevereiro de I 968, "a insana luta dos epemistas chegou ao fim", com a assinatura de decreto presidencial federalizando o Hsp. Medida que apesar do entusiasmo estudantil não se concretizou.

O livro agora publicado, comemorativo dos 75 anos da instituição, pela primeira vez interpreta e coloca em perspectiva o processo da evolução da escola privada que se transformou em universidade pública. Evolução que teve como pano de fundo uma guerra mundial e mudanças traumáticas de regime político no país. O livro mostra que a instituição foi criada, consolidada e desenvolvida não pela ação decisiva de poucos indivíduos, mas como resultado do trabalho de sucessivas geraçôes de professores sintonizados com seu tempo e sua circunstância. Ou nos versos de João Cabral:

Um galo sozinho não tece uma manhã: ele precisará sempre de outros galos. De um que apanhe esse grito que ele e o lance a outro; de um outro galo que apanhe o grito que um galo antes e o lance a outro; e de outros galos que com muitos outros galos se cruzem os fios de sol de seus gritos de galo, para que a manhá, desde uma teia tênue, se vá tecendo, entre todos os galos. 
A primeira geração criou uma escola de ensino profissional, seu hospital-escola, e nucleou a pesquisa. A segunda geração consolidou uma instituiçáo de pesquisa de categoria internacional, criou uma universidade e transformou a SPDM em uma das maiores empresas brasileiras no setor de prestação de serviços na área da saúde. Cabe à próxima geração desenvolver um projeto de transformar a universidade de pesquisa em universidade global, capaz de atrair talentosos estudantes e pesquisadores do mundo todo.

Este livro lembra que não existe criação sem tradição que a nutra, assim como não existe tradição sem criação que a renove. Ou nos versos de T. S. Eliot:

Time present and time past

Are both perhaps present in time future

And time future contained in time past. 